\title{
Cohort-Based Doctoral Programs: What We Have Learned Over the Last 18 Years
}

\author{
Krishna Bista \\ University of Louisiana at \\ Monroe, Monroe, Louisiana, USA
}

bista@ulm.edu

\author{
David W. Cox \\ Arkansas State University, \\ Jonesboro, Arkansas, USA
}

dwcox@astate.edu

\begin{abstract}
This paper assesses student perceptions and includes student reflections pertaining to a cohort model doctoral program in Educational Leadership (EdD) at a Southern university in the United States. Based on the open-ended comments and survey responses from 48 participants who graduated with this degree, the cohort-based doctoral program was found to have met the needs of the students. Conclusions and recommendations are drawn based on extensive literature on cohort based EdD program and findings from this case study about one cohort model degree program.
\end{abstract}

Keywords: cohort-based doctoral program; educational leadership; higher education

\section{Introduction}

Over four decades the cohort-based model in higher educational programs has been increasingly popular in the United States, the United Kingdom, Canada, and elsewhere. The rationale for the development of this model is associated with higher student retention rates as well as the optimal shared educational experience of the cohort members (Lei, Gorelick, Short, Smallwood, \& Wright-Porter, 2011; Maher, 2005). According to Seifert and Mandzuk (2006), the cohort-based education model develops mutual and intellectual stimulation, forms social ties, and enables the institutions to organize the programs in effective ways. Nimer (2009) mentions that the cohortbased doctoral program offers its members an integral part of personal and professional support for academic interaction and degree completion. In such shared learning communities, educators have agreed that development of a strong social and professional network among the professors and students will positively impact student performance (Hyatt \& Williams, 2011; Nimer, 2009; Williams \& Simpson, 2010).

Doctoral programs in Educational Leadership (EdD) at institutions of higher education in the

Material published as part of this publication, either on-line or in print, is copyrighted by the Informing Science Institute. Permission to make digital or paper copy of part or all of these works for personal or classroom use is granted without fee provided that the copies are not made or distributed for profit or commercial advantage AND that copies 1) bear this notice in full and 2) give the full citation on the first page. It is permissible to abstract these works so long as credit is given. To copy in all other cases or to republish or to post on a server or to redistribute to lists requires specific permission and payment of a fee. Contact Publisher@InformingScience.org to request redistribution permission.
United States are mostly built on a cohort-based model in order to develop leadership skills, advanced research skills, critical thinking skills, and problem solving skills for various administrative and leadership positions. Loyola University at Chicago (2011) defines a cohort as a group of students who works through a program sequence 
together to achieve the same academic degree.

According to Hyatt and Williams (2011, p. 54), EdD programs commonly "integrate interdisciplinary theories from other fields including education, psychology, philosophy, and organizational studies." Such programs allow leadership students and practitioners to think radically new thoughts in their workplaces - non-profit organizations, K-12 schools, higher education, and government (Rost, 1991). Bentley, Zhao, Reames and Reed (2004) have defined the cohort features as "frames" and "metaphors" for group learning and sharing knowledge, experience and support which capture the essence of their experience at Auburn University's EdD program. Based on Bolman and Deal's (2013) reframing organization's model, Bentley et al. (2004) identified the underlying structures of the program according to four interpretative frames: 1) a political frame (people coming together to interact in the class through a group philosophy), 2) the structural frame (roles and formal relationships), 3) a human resources frame (cohort members as a family, support and resources for collaboration and professional growth), and 4) a symbolic frame (learning, culture, traditions, beliefs and emotions).

However, these earlier studies were descriptive in nature (Bentley et al., 2004; Lei et al., 2011; Nimer, 2009; Seifert \& Mandzuk, 2006). This paper evaluates the success of the cohort-based model educational leadership program through the eyes of the doctoral students. To reduce extraneous variability, the paper focuses on students in a doctoral program in Educational Leadership at XYZ University in the United States as a case study of a single cohort model. The paper starts with an extensive literature review in cohort model EdD programs. The paper also explores the strengths and drawbacks of the cohort-based model. The following research questions guided this study:

a) What were the perceptions of graduates about the cohort-based model EdD program? and

b) What were their overall experiences while earning the EdD degree?

\section{Overview of Doctoral Programs in Educational Leadership (EdD)}

There is a well-established tradition of doctoral programs in Educational Leadership across the United States. The first Doctor of Education (EdD) was granted at Harvard University in 1921, then at Teachers College in 1934 (Toma, 2002). In England, the first EdD degree was awarded at the University of Bristol in 1992. Today, many universities in more than 30 countries are offering cohort-based doctoral programs. Such university graduate leadership programs prepare students for college administration and leadership. Educators and researchers do not see significant differences between traditional $\mathrm{PhD}$ degrees and $\mathrm{EdD}$ degrees in education in terms of dissertation research quality and other outcomes (Augusto, 2009; Baez, 2002; Hallinger, 2011). However, many universities, including top-tier universities in the U.S. (e.g., Harvard University, University of Southern California, Vanderbilt University), have redesigned their doctoral program in education within the past decade emphasizing practice over scholarship and school-based improvement over university level teaching (Purinton, 2012). For instance, the University of Missouri redesigned its EdD curriculum in order to achieve higher levels of cognitive learning outcomes (Mountford, 2005).

The EdD programs are tailored with different research and practitioner course components at various institutions of higher education with a specialization in Leadership, Curriculum Instruction, Community College Administration, Special Education, Higher Education, and/or Educational Policy. Designed for working-adult students, the cohort model educational leadership programs are administered in a majority of master's and doctoral degrees granting universities in the United States. Based on student populations, faculty numbers, and the mission of institutions, cohort-based models are described and designed as flexible open-cohort or as restrictive closed- 
cohort formats. A closed-cohort is a group of purposeful students entering and pursuing a program of study together "characterized by social and cultural processes, shared experiences and interactions, collective efforts and mutual commitments to an educational goal" (Pemberton \& Akkary, 2010, p. 180). In a closed cohort model, new students are never added once the cohort is underway. In contrast, an open-cohort is defined as flexible program (dynamic) as need of students and departmental mission where new members can leave or be recruited over time (LaMorte, 2012; Pemberton \& Akkary, 2010).

\section{Educational Leadership Program at XYZ University}

The EdD in Educational Leadership program at a Southern university (called XYZ University in this study) started in 1992 as a closed cohort program. It was accredited by National Council for Accreditation of Teacher Education and Higher Learning Commission. The goals of this doctoral degree are to "increase the knowledge and skill in educational administration, enhance research skills, and provide the necessary credentials for those desiring to pursue a career in higher education or in the public school setting" (Student Handbook, 2012, p. 15). The conceptual framework of this doctoral program is designed around four themes--self, change process, organization, and leadership. Self is designed and defined as a synthesis of values and traits that examines personal values and purposes toward professional maturity. Change is conceived as an "inevitable process in which new, discernible patterns of action develop in the culture or behavior of people and organizations" (Student Handbook, 2012, p. 15). Organization is taken as a venue for the dynamic interaction of people, their values, needs, expectations, and accomplishments. Leadership is defined as "the act of encouraging interaction and inspiring vision to facilitate a process of organizational change" (Student Handbook, 2012, p. 16). The EdD program focuses on the following six components: 1) Doctoral knowledge core -45 credits; 2) Research Foundations -9 credits; 3) Socio-Cultural Foundations -3 credits; 4) Psycho-Behavioral Foundations -3 credits; 5) Leadership Foundations -18 credits; 6) Cognate Area/Leadership Electives -21 credits. This program requires a total of 99 credits beyond the bachelor's degree. In addition to course work and dissertation, students are required to pass the comprehensive examination which includes three of the following four parts: cohort project, individual written exam, capstone narrative, and presentation or publication or grant writing.

The program allows practitioners to pursue a doctoral degree through the cohort model while remaining in their current position. At XYZ University, courses meet once a week from 4:00 pm to $10: 00 \mathrm{pm}$ throughout the academic year. The full course load for domestic students is six credit hours and nine credit hours for international students. The requirement for admission to the EdD in Educational Leadership degree is competitive based on Standardized tests (Graduate Record Examination or Millar Analogies Test) and other requirements such as previous publication records, writing samples, and recommendations. Each year, a cohort of 15 students enters into the program. Each student is assigned a faculty advisor at the time of the offering of admission based on the experience, education, and goals of the applicant. In most cases, the faculty advisor becomes the dissertation advisor. To complete the core courses, i.e., 45 hours, students take two courses at a time physically on-campus once a week for 21 months. After the successful completion of course work, students pursue their individual dissertation research (see, Figure 1). 


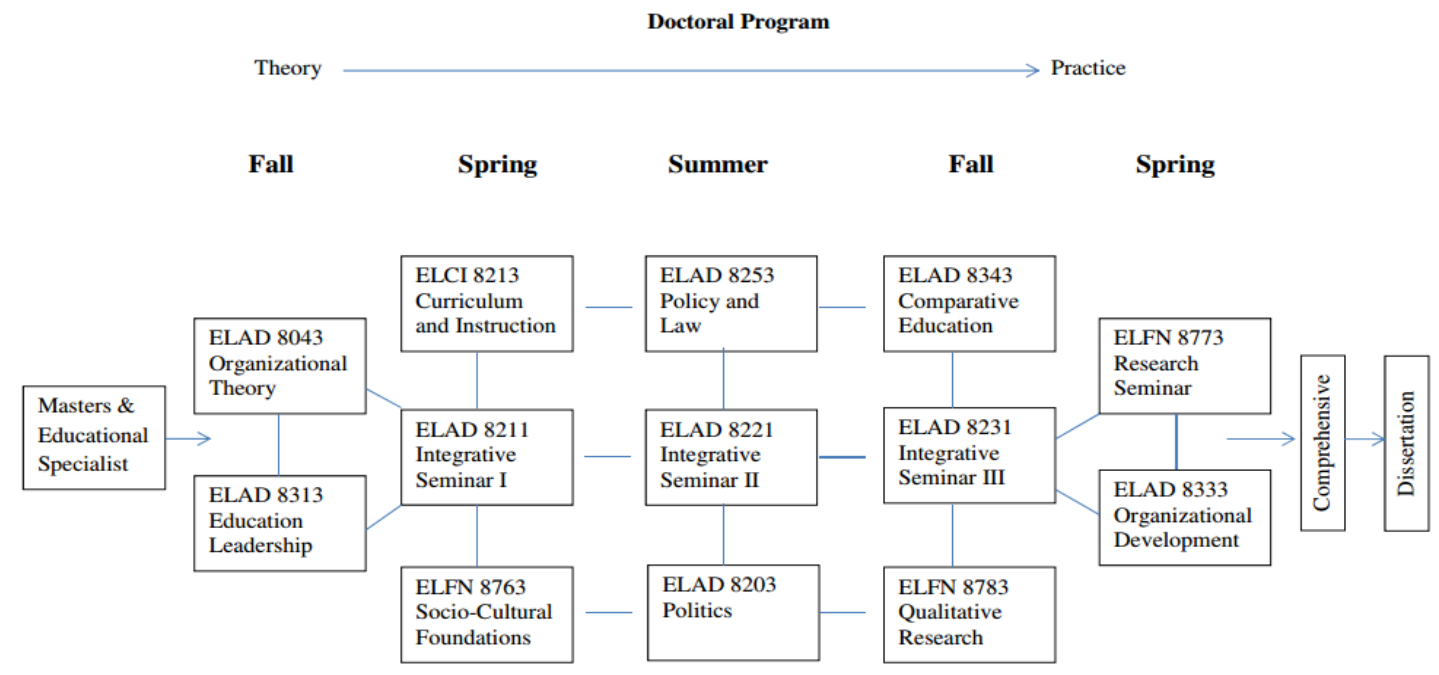

Figure 1. EdD Course Sequence at XYZ University

\section{Related Literature}

\section{Cohorts and Cohort-Based Model}

In educational doctoral programs, cohorts are defined as "a group of about 10-25 students who begin a program of study together, proceed together through a series of developmental experiences in the context of that program of study, and end the program at approximately the same time" (Lei et al., 2011, pp. 497-498). Such a cohort-based model fosters the dynamics of group cohesion. California State University has defined its cohort-based model doctoral programs as "a group of students moving through all classes and phases of the program together. Students benefit from Mutual academic, emotional, and logistical support for program success and timely completion; camaraderie and collaborative learning with experienced colleagues; and lasting personal ties and professional networks that aid in career development, ongoing professional growth, and reform initiatives across schools, districts, or colleges" (The Cohort Model, 2012).

Although the cohort-based model appeared from the beginning of the 1980s, educators have constantly debated and reported how the cohort-based model is successful compared to noncohort counterparts. Cohort-based model doctoral programs are beneficial for both part time students and full time students and such programs are well received across the globe (Gardner \& Gopaul, 2012). Freeman and Kochan (2012) examined university presidents' perceptions of their academic doctoral preparation programs at various universities in the United States. Students found the cohort-based model doctoral programs helpful in four competencies areas:

interpersonal development, personal attributes, management, and communications. In their study, many administrator participants shared that the cohort-based model doctoral program as a tool of "socialization mechanism into the academy" (Freeman \& Kochan, 2012, p. 103) without leaving a full time job. Existing literature (Govender \& Dhunpath, 2011; Poole, 2011) has shown that educational cohort doctoral programs have been successful in many countries outside the United States. For instance, Poole (2011) conducted research on teaching and supervision of EdD programs at $16 \mathrm{UK}$ universities and found that doctoral education degrees internationally were very popular in the context of globalized competition for jobs. Poole (2011) writes, "Across British universities, the structure of EdD programmes varies somewhat, but tends to feature first a number of courses or modules (assessed through assignments) and subsequently the writing of a 
thesis" (p.50). Similarly, Govender and Dhunpath (2011) examined the experiences of a cohort doctoral program $(\mathrm{PhD})$ at the University of KwaZulu in South Africa. Their study confirmed successful collaboration and collegiality among students and supervisors as well as the cohort model offered new insights for faculty to bring changes in their doctoral programs.

There are a number of variations in the design and practices of cohorts model across educational leadership (EdD) programs. Barnett and Caffarella (1992) have suggested the following elements as necessary to have a successful cohort structure: a) Improved admission criteria for qualified candidates; b) Instructional delivery mechanisms for cohort interactions, reflections and learning opportunities; c) Involvement and connection between new and old cohort members, and d) Responsiveness to adult learner experiences. Both subjective predications including reference information and objective information such as past academic performance (grade point average) are indicated as strong admission criteria to EdD doctoral programs. Young (2007) studied 102 applicants seeking admission to doctoral program in educational leadership from 1991 to 2001. His findings suggested that an adequate selection decision brings positive outcomes in the program. In another quantitative study, Mountford, Ehlert, Machell, and Cockrell (2007) found that personal screening measures (interviews, on-site and real-time problem solving activities, and timed writing activities) were more accurate predictors of students' performance in leadership program than the traditional screening measure (GRE score and GPAs).

In the next section, we review existing empirical research that focused on the strengths and weaknesses of the cohort model.

\section{Strengths of Membership in a Cohort-Based Model}

The cohort membership includes a number of benefits at the doctoral level study. McCarthy, Trenga, \& Weiner (2005) have described the importance of a shared culture to enhance social, personal, and educational outcomes. A cohort-based model helps students solve problems independently and accomplish goals seeking the assistance of peers (Lei et al., 2011). Some scholars have focused on students' participation in both traditional and non-traditional learning through the social progress in leadership programs (John-Steiner \& Maher, 2003; Wesson, Holman, Holman, \& Cox, 1996).

As students in cohorts collaborate on tasks and assignments, this generates a group of people with similar academic and professional goals. This encourages faculty to work closely with the group of such students. Seed (2008) mentioned a positive peer relationship that forms familial and emotional ties, team views, and team responsibilities. As a part of learning together, the cohort groups to celebrate birthdays, share meals, and provide academic and psychological support to members (Lei et al., 2011; McCarthy et al., 2005). Lei and colleagues (2011) report that the familiarity among cohort members allows for an authentic conversation about issues, concerns, and projects in the class compared to non-cohort members. Lei and colleagues write (2011, p. 499): "Cohort members truly appreciate the active, ongoing support and learn to trust each other. Sometimes, students in a cohort come together and have a collective voice when addressing certain issues to their instructors." Studies have supported that the power inherent in a cohort model provides mutual support and protection (Basom \& Yerkers, 2001; Lewis, Ascher, Hayes, \& Ieva, 2010; Potthoff, Batenhorst, Frederickson, \& Tracy, 2001). In cohort-based models, students receive support and encouragement from faculty and peers on a particular challenging assignment (Ivakova \& Stick, 2007; Spaulding, \& Rockinson-Szakiw, 2012). In such shared learning communities, students form a bond based on interests, gender, academic knowledge, and social awareness to pursue the goals by sharing personal stories and school related experiences. They report and update incidents of mutual care and encourage individuals to stay in the program. As in a family, the cohort members are resources for each other for academic, personal, and social support. A cohort model doctoral degree has been beneficial for older, part-time students, 
married, and parents with home and childcare responsibilities because of support they received from fellow classmates during their study (Sax, 2008; Tokuno, 2008). Pemberton and Akkary (2010) examined seven female participants' lived experiences in a cohort-based doctoral program where the participants reported that they perceived the program helped them understand individual and collective experiences of each other while pursuing the degree.

At a professional level, the cohort members enjoy more opportunities such as pursuing proposals for conferences, co-authoring manuscripts for publication, serving as guest lecturers for university courses, and co-teaching with professors (Lewis et al., 2010). Membership in the cohort models improves academic success and members describe cohort participation as being "intellectually stimulating" (Eifler, Potthoff, \& Dinsmore, 2004, p. 97). The unique cohort structure offers members the opportunity to "interact with the materials and therefore internalize and globalize the information" (Lewis, et al., 2010, p. 4). Members in a cohort help each other navigate financial issues, departmental policies, class registration, and academic guidance (Lei et al., 2011; Unzueta, Moores-Abdool, \& Donet, 2008). McPhail, Robinson and Scott (2008) examined leadership development experiences (characteristics and behaviors) of 50 doctoral students in their study at Morgan State University. As strength of the cohort model, they found the structure, instructors, networking, and curriculum of the program successful components which the cohort members enjoyed in their doctoral journey.

\section{Cohort Membership Drawbacks}

The cohort members become successful only when mutual collaboration of faculty members, departments and administrative structures exist within the university system. Students sometimes feel ignored and isolated when they do not receive enough support and attention from faculty and administration. Failure to understand and accept the cohort expectations, norms and values may lead to a friction between student and faculty. Lewis et al. (2010, p. 5) write, "Having students grouped together in cohort models for the duration of the program results in personality conflicts that are not a one-class issue. If students have difficult interpersonal conflicts, these may influence the members throughout the life of the cohort." As a result of class discussion or group projects, sometimes students may come with personality conflicts over the duration of the program, and that eventually becomes the fear for groups of students in the cohort. Teitel (1997, p. 72) wrote, "If there was a conflict between students, we would have to deal with that for four years." Studies show that the cohort group can have a power and possibility to alter policy of cohort models because of disruptive group expectations of behaviors like the members of a dysfunctional family (Lewis et al., 2010; McCarthy et al., 2005; Seed, 2008). Unzueta and colleagues (2008) have reported that cohort members, working on different projects and studying together with the same group of students throughout the program, receive limited interactions and growth of knowledge. Because of the required course sequence, the cohort members also may not have opportunity to take courses outside of the cohort program and understand different philosophies and policies on educational perspectives. In her qualitative study, Maher (2005, p. 203) has reported cohort personalities and conflicts as one of the disadvantages:

Some students noted difficulty in collaborating with different personality types and a sense that group members were intellectually mismatched. In these cases, students described group participation as little more than an obligation to be fulfilled. As one student commented, "I just don't always feel like there is a lot of depth of interaction there, but we get done what we need to get done.

It may further create competition instead of teamwork, resentment instead of cohesion and trust (Lei et al., 2011). In their study, McPhail, Robinson and Scott (2008) noticed some factors such as "dominant group members, traditional instructional modalities, and inadequate facilities negatively impacted perceptions of the cohort experience" (p. 362). 
Although there are several advantages of a cohort model, it is hard to predict the outcomes of every EdD program with similar expectations because the growth of the cohort depends on demographics. The department or university may enroll students with administration backgrounds or K-12 or higher education, or non-educational degree backgrounds, and these may affect the balance in the cohort. There is no research on how such demographics affect the group dynamics. For instance, cohort members with a Master of Business Administration background or a Master of Science in Nursing share different perspectives compared to students from educational degree backgrounds. There is also little research specific to technological skills necessary for doctoral students and faculty in leadership programs. Many students in EdD programs may expect a variety of technological tools used to meet their full time enjoyment and complete the degree program at the same time. Courses offered via online platform or hybrid mode may be a challenge for adult students who have limited knowledge of recent technologies. To address such a gap, it is important to take a case/sample of groups of cohort graduates and explore their experiences about the program.

\section{Research Method}

To answer the study research questions, the researchers used a mixed methods approach (Tashakkori \& Teddlie, 2003) which is a procedure for collecting, analyzing, and integrating both quantitative and qualitative data (Creswell, 2005; Ivankova \& Stick, 2007). The rationale for a mixed methods design for this study was to capture the trends and details of the learning explained from student perspectives. The quantitative data helped identify a general picture of the doctoral program in educational leadership using a descriptive statistics. The qualitative data provided a more in-depth conceptualization of the learning experience.

The researchers used simple statistical measures to explore variations in key variables across the doctoral program components. The participants shared their responses on a five point Likert scale where $1=$ strongly dissatisfied, and $5=$ highly satisfied. The authors did not perform any advanced statistical analysis due to the small number of variables.

To ensure construct validity, the researchers examined the use of multiple sources of evidence including graduate catalog, student handbook, and existing studies related to cohort-based doctoral programs. The researchers also worked with other doctoral faculty and graduate assistants of educational leadership program regarding the web-based survey instrument, and program outcomes. This study was based on the patterns and trends first identified by the faculty of educational leadership program at XYZ University (Holman, Oleson, \& Wesson, 1996; Wesson et al., 1996) and then they were replicated in this study. Reliability looks at how well the study can be replicated (Merriam, 1998) and in this study, the researchers simply replicated the previous studies with some modification in the instrument.

\section{Setting and Participants}

The research setting for this study was a doctoral educational leadership (EdD) program for K-12 and higher education practitioners offered at XZY University, a public university in the United States. The university enrolls a cohort of 15 students in the fall semester of each year. The doctoral program was started in 1992. Approximately 242 students have been admitted in EdD cohorts in the last 18 years. An online survey was conducted in September 2011 at XYZ. To better understand the effectiveness of the doctoral program, 98 students, all of whom have graduated from the doctoral program were invited to participate in the survey. The main reasons for choosing an online survey were lower research cost, ease of access to participants, faster responses, and participants being comfortable with responses. The Department has updated email address of graduates of EdD programs from the first cohort to current cohorts, but the researchers could not reach all graduates of the program because of a gap of time. After the approval of 
Institutional Review Board (IRB) for human subjects, the Department administered the survey to 98 students whose emails were accurate.

\section{Instrumentation}

The survey comprised of six sections including the following: a) curriculum - items include course content, instructional materials, learning experiences, course requirements, relevance; $b$ ) program structure - items as scheduling of classes, requirements for the degree (credit hours, comprehensive exams), scope and sequences, cognate and residency, clarity of policies and procedures, manageability of load; c) faculty - quality of teaching, knowledge of field, professionalism, currency, expectations, qualifications, ability to stimulate and motivate students, advisement, availability for consultation, feedback on student performance, grades and grading; d) learning environment - student-peer relations, library resources, facilities, coordination among, and supportive atmosphere; e) outcomes - development of new insights and perspectives, and applicability of courses to professional life; and f) overall evaluation-ability to complete the program and dissertation. Reliability Statistics of six items (curriculum, program, faculty, learning environment, program outcomes and overall evaluation) indicated Cronbach's Alpha 0.85, and Cronbach's Alaph based on standardized items was 0.85 based on 48 responses. The participants were asked to rate the items on a five point Likert scale in which $1=$ strongly dissatisfied; $2=$ not satisfied; $3=$ neutral; $4=$ satisfied; and $5=$ highly satisfied. This survey instrument (Holman et al. 1996; Wesson et al., 1996) was developed and implemented by the EdD doctoral faculty of XYZ University from 2001 to 2005. Initially, this instrument was developed to assess the quality of the program at the university and accreditation updates. However, the instrument was not administered to the cohorts since 2005. For the purpose of qualitative data collection, open ended items were added in the survey to understand the participants' experiences, comments, and suggestions regarding the program.

The survey did not include any demographic items such as age, sex, socio-economic status, previous college/university, marital status, and current occupation assuming that participants may feel reluctant to participate in the survey. The researchers also assumed that students were familiar with each other as members of a closed cohort. However, the participants were asked to indicate which cohort they belonged to at the doctoral program of XYZ University. The responses and opinions of participants were collected within a week.

The researchers analyzed the quantitative data using descriptive statistics. Out of 98 graduates (who have completed course work, dissertations and earned diplomas) from eighteen cohorts, 48 $(N=48)$ responses were returned with a $49 \%$ response rate.

\section{Results and Findings}

This report includes reflections of $48 \mathrm{EdD}$ graduates $(N=48)$ who participated in an online survey study that was administered in September 2011. As seen in the Figure 2, a good response rate was returned from the first cohort and cohorts $9^{\text {th }}$ through $15^{\text {th }}$. There is a low response rate from the cohorts $2^{\text {nd }}$ through $8^{\text {th }}$ and the reasons could be the survey did not reach participants by not having recent email address or participants did not graduate from the program. Responses from graduates in recent cohorts $\left(16^{\text {th }}, 17^{\text {th }}\right.$ and $\left.18^{\text {th }}\right)$ were low; this could be because these individuals were working on their dissertations, and therefore they were not invited to participate to in this study. A limitation of the study is that data from only certain cohorts may not be representing of the total group of 98 graduates. 


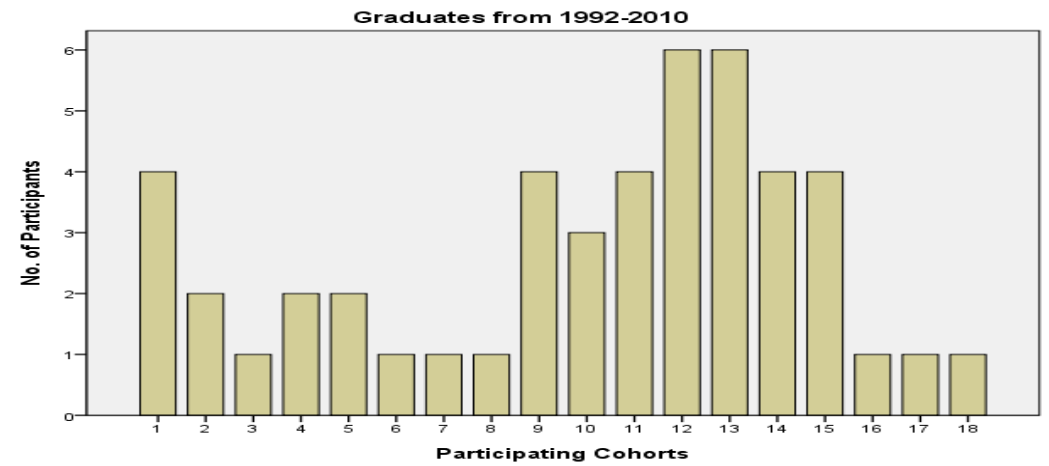

Figure 2. Participating Doctoral Cohorts from 1992-2010

The responses received from the six categories were Curriculum (Mean 4.48), Program Structure (Mean 4.67), Faculty (Mean 4.50), Learning Environment (Mean 4.65), Outcomes (Mean 4.58) and Overall Evaluation (Mean 4.48). The results of the six components indicated support for the cohort program.

\section{Curriculum}

The Curriculum component asked participants to share their perceptions on course content, instructional materials, learning experiences, course requirements, and relevance. The debate over knowledge as either objective or subjective community of practice, and curriculum as an explicit structure for organizing student knowledge and cultural engagement were included.

Based on their knowledge or perceptions of curriculum used throughout the cohort doctoral program, participants in this survey rated this component as satisfied. Table 1 shows students were satisfied with the curriculum of this program.

Table 1. Curriculum

\begin{tabular}{llccccc}
\hline & Count & $\%$ & $M$ & $S D$ & Skewness & Range \\
\hline 1. Strongly Dissatisfied & -- & -- & 4.48 & 0.71 & -1.752 & 3.00 \\
2. Not Satisfied & 2 & 4.2 & & & & \\
3. Neutral & -- & -- & & & \\
4. Satisfied & 19 & 39.6 & & & \\
5. Highly Satisfied & 27 & 56.3 & & & \\
$\quad$ Total & 48 & 100.0 & & & \\
\hline
\end{tabular}

Note. $\mathrm{N}=48$

From the open ended responses, it is further insightful to predicate what participants felt overall about the cohort based EdD program at XYZ University. One participant mentioned:

I was interested to verify from the curriculum and professorial experiences if my conclusions drawn from over 25 years in a higher education career were worthy. The curriculum helped identify how education should be and professors verified that my individual conclusions were accurate.

The participants acknowledge the four themes of the doctoral program - Self, Leadership, Change Process, and Organizations - were closely tied together in the doctoral curriculum. 
Another participant shared, "The curriculum was comprehensive and rich in content. I felt that course content was very relevant. Curriculum was balanced, comprehensive, and rigorous." One participant told us in the survey that the chosen curriculum and regular class discussion being helpful, "Tremendous discussions.... Everything was relevant to the real world of public education. EdD courses fully prepared me for work as an educational practitioner in higher education."

Although the majority of comments were positive, a few participants shared areas to improve in curriculum to the needs of current generation. One participant mentioned a focus requiring an intensive statistical class. The cohort EdD program at XYZ University enrolls students from both K-12 and higher educational backgrounds. In this context, to better enhance the goals of individuals, a participant recommended a need for additional specific doctoral program specializing in individual career goals in higher education administration and school administration, "The Higher Education Program and K-12 Program should be two different programs in order to effectively meet the needs of the students. Additionally, the faculty with K12 backgrounds should stay connected to the public school districts in order to stay current on trends, issues, new accountability requirements." This recommendation is supported by another comment, "At the time I was enrolled, the curriculum was designed with greater emphasis on public schools. I was working on educational leadership with emphasis on higher education." A comment mentioned an additional focus on writing and publication:

I think improvements can be made in a couple of areas. 1. Include more content on 'culturally responsive instruction' and 'culturally responsive pedagogy' 2 . Add a 'writing for publication' course if possible, for those who wish to teach in higher education. It does not have to be one of the core courses; it could be one of the "strongly recommended" pre-requisites. 3. I think some sort of internship would be great too. 4 . We had a textbook oriented system, one that I was, and still am not very fond of. 5. I love the portfolio that we put together - I hope students still do it. 6 . I think the reflections that we do are great, but honestly, students need more scaffolding. They need to be taught HOW to reflect. Students often wrote reflections five minutes before class and I wonder how much substance they really had. I was rather frustrated with this 'casual' attitude towards such a meaningful activity that I did my first empirical study at XYZ with masters' level students and discovered some interesting trends.

Overall, students expressed the curriculum was relevant to their current profession and/or prepared them for their prospective careers in K-12 or Higher Education. Some students noticed adding publication writing courses as pre requisites, and forming separate emphasis areas of the program: K-12 and Higher Education would enhance the doctoral program.

\section{Program Structure}

The doctoral program structure category measured student perceptions of class schedule, degree requirements (credit hours, comprehensive exams), scope and sequence of curriculum, cognate and residency, clarity of policies and procedures, and manageability of load. Table 2 shows students were satisfied with the structure or organization of this program. 
Bista \& Cox

Table 2. Doctoral Program

\begin{tabular}{llccccc}
\hline & Count & $\%$ & $M$ & $S D$ & Skewness & Range \\
\hline 1. Strongly Dissatisfied & -- & -- & 4.67 & .048 & -.730 & 1.00 \\
2. Not Satisfied & -- & -- & & & & \\
3. Neutral & -- & -- & & & \\
4. Satisfied & 16 & 33.3 & & & \\
5. Highly Satisfied & 32 & 66.7 & & & \\
\multicolumn{2}{c}{ Total } & 48 & 100.0 & & & \\
\hline
\end{tabular}

Note. $\mathrm{N}=48$

Individual comments about the structure of the EdD program suggest the participants enjoyed the proximity and flexibility of the program. A participant shared, "I loved having two professors, I love the way the courses were sequenced. I especially like when we provided scaffolding and encouraged to think about our dissertation right from the start, through the three workshops (can't remember what they were called) and that we were forced to write the three chapters during Dr. 's class." Another participants also emphasized this feature of having regular classes in evenings and seminars in weekends, "The cohort met on the same night each week, and it extended thorough the entire program. It was easy to work around my job and personal life. Scheduling is perfect for those persons who are employed." The third comment also follows the first two participants:

I think that the class schedules and load were all very well manageable. They were great for working people! The emphasis of a cohort format places structure into the progression through the program. Scheduling two classes back to back one night a week allows most to retain their full-time work and still progress through the program. Comprehensive exams might have a place in a PhD format but not in the EdD. The current options make sense for the EdD applications.

Only a few participants shared that they liked the four components of the comprehensive exam structure in which they can select cohort project, individual written exam, portfolio and presentation or publication or grant. One participant expressed, "I especially appreciate the opportunity to have an alternative to a high-stakes written comprehensive exam. Even though all the alternatives involved much more work, alternatives such as a portfolio allow for a much more reflective and meaningful learning experience as well as a much more effective way to communicate learning on a personal, integrative level." In 2010, the faculty had changed the option of portfolio into narrative capstone to meet the current needs of graduates. One participant wrote,

I would suggest some on-line offerings when possible for convenience and to attract more students. At the time that I completed the once a week travel to campus was manageable, but technology has progressed and perhaps a few trips onto campus with online requirements would be an option.

Students enjoyed the doctoral program's convenience of only meeting one night per week and having just two professors per semester. They also spoke favorably of the alternatives to the Comprehensive Exam structure. Room for improvements included one student stating an alternative to the current summer semester structure for the doctoral program should be considered, while another student believed that including on-line classes in the program should be an option. 


\section{Faculty}

The Faculty category measured student perceptions on professors teaching quality, pedagogical expertise, professionalism, involvement, expectations, qualifications, motivation, advisement and feedback, availability, and grades. Table 3 shows a majority of participants satisfied with faculty and two participants not satisfied.

Table 3. Faculty

\begin{tabular}{llccccc}
\hline & Count & $\%$ & $M$ & $S D$ & Skewness & Range \\
\hline 1. Strongly Dissatisfied & 1 & 2.1 & 4.50 & .83 & -2.371 & 4.00 \\
2. Not Satisfied & 1 & 2.1 & & & & \\
3. Neutral & 1 & 2.1 & & & \\
4. Satisfied & 15 & 31.3 & & & \\
5. Highly Satisfied & 30 & 62.5 & & & \\
\multicolumn{2}{c}{ Total } & 48 & 100.0 & & & \\
\hline
\end{tabular}

Note. $N=48$

Participants in the open ended survey expressed positive attributes of the EdD cohort model and faculty. One participant wrote, "They [faculty] were all good role models and excellent instructors. The faculty in the doctoral program was easily accessible, approachable, and a variety of expertise was included. I had an outstanding advisor and my committee was very helpful." A second participant wrote, "The faculty is very helpful and caring. They treat students very well and respect their opinions." The third participant mentioned, "Faculty was outstanding in every way - very professional, supportive, and maintained rigor and high expectations." The forth comment was about male and female faculty, "I was highly satisfied with the exception of one faculty member. Also, when I went through the program there were no women teaching and I did not feel the faculty took into consideration that women and men approach things differently." The fifth participant also shared strength of faculty, "The faculty members were outstanding on all their fields, and Dr. was the BEST teacher I have ever had. I truly enjoyed my time on the doctoral program. Nearly all CEE [department] faculty seemed motivated to assist EdD students to succeed in the program."

In this study, some participants shared some negative comments and suggestions for faculty development. One participant mentioned,

I felt like the teaching staff in the department was great. I did see a contrast between what we were being taught and what was accepted in class. We were taught to be leaders, open to new experiences, and be aware that the traditional methods of teaching might not always be what it best. However when exploring some of these issues at times some professors seemed unwilling to be open minded to new experiences that students were encouraged to explore.

Two participants mentioned about grading and reflections/journal writing as a part of regular assignments. The first participant shared, "I do not feel grades should be given for reflective journals, if they are still graded. A reflective journal should be an individual's personal thoughts." The second participant wrote, "I loved the different personalities, the different teaching styles. I have mixed feelings about the grading system - I think everyone got an A in almost all classes. I think the only professor that went out on a limb and "dared" to give students a B was Dr. One participant mentioned about what s/he liked, "Obviously, there were some classes that I felt like I learned more in than others. The theory courses were my least favorite. I like relevancy and 
most of the courses were relevant and motivated me to grow as a leader." Another dissatisfied student boldly mentioned s/her reactions as, "Faculty should be mature enough to encourage their students to engage in adult topics and conversations. Everyone will not agree on outcomes necessarily, but should be mature enough on both sides to allow everyone to have the conversation and not harbor ill feelings!"

In summary, a majority of students expressed their opinions that the faculty members were caring and helpful to the students. In addition, students stated that faculty members were very knowledgeable about the material they presented, and offered different perspectives on topics in class discussions. However, some dissatisfied students told us in the open ended survey that they were not happy with faculty, grading system and practice of some traditional assignments like journal writing or reflections.

\section{Learning Environment}

The Learning Environment component evaluated student-peer relations, library resources, facilities, faculty cohesion, and supportive atmosphere. Table 4 indicated that all participants were satisfied with the learning environment offered to EdD cohorts at XYZ University.

Table 4. Learning Environment

\begin{tabular}{llccccc}
\hline & Count & $\%$ & $M$ & $S D$ & Skewness & Range \\
\hline 1. Strongly Dissatisfied & -- & -- & 4.65 & 0.53 & -1.083 & 2.00 \\
2. Not Satisfied & -- & -- & & & & \\
3. Neutral & 1 & 2.1 & & & \\
4. Satisfied & 15 & 31.3 & & & \\
5. Highly Satisfied & 32 & 66.7 & & & \\
\multicolumn{2}{c}{ Total } & 48 & 100.0 & & & \\
\end{tabular}

Note. $N=48$

The participants shared their positive comments about the learning environment. One participant mentioned, "We had excellent library resources, a wonderful inter-library loan system, which was not used enough by our students. Please consider getting the librarian in during the orientation session, to show how the library can be used more effectively." Another participant wrote, "I enjoyed our learning environment. It was a very small room, but we were a small group, so there was no problem there. We felt like a family." A participant acknowledged the cohort ties as, "I was able to make many lasting friends through my cohort experience. I am very glad for that format. It builds a lasting relationship that is priceless." Another participant shared, "The cohort model allows for students to work together on projects and to network for future success. Very accommodating; advanced technology available."

In short, students liked the small cohort-based program; they experienced the small numbers allowed for extensive collaboration and allowed for the faculty as well as the students to get to know one another from a more individual perspective. Students were fond of the lasting relationships that were formed during the semesters of coursework, and enjoyed networking opportunities that the cohort provided.

\section{Outcomes}

The Outcomes component looked at students' development of new perspectives and applicability of courses related to career. In this section, 44 students mentioned they were satisfied with the 
program in their current jobs and four students were neutral. Although, this survey did not ask about their current occupation and how the EdD cohort model doctoral degree in Educational Leadership helped them find new job or current position, the following results (Table 5) show participants are satisfied with the education they received at XYZ University.

Table 5. Outcomes

\begin{tabular}{llccccc}
\hline & Count & $\%$ & $M$ & $S D$ & Skewness & Range \\
\hline 1. Strongly Dissatisfied & -- & -- & 4.58 & 0.65 & -1.308 & 2 \\
2. Not Satisfied & -- & -- & & & & \\
3. Neutral & 4 & 8.3 & & & \\
4. Satisfied & 12 & 25 & & & \\
5. Highly Satisfied & 32 & 66.7 & & & \\
$\quad$ Total & 48 & 100.0 & & & \\
$\quad$ & & &
\end{tabular}

Note. $N=48$

Among positive comments received from participants, a participant mentioned the outcomes of research class in current position this way,

I learned the value of research, and how exciting it can - thanks to Dr. and Dr. . I learned the value of great pedagogy and the need to constantly innovate from

Dr. and Dr. . From Dr. I learned the power of networking, being a great resource person and MBWA. Dr. was the one who came down on me for terrible APA - I will always remember that B and thank you for it. I have completed three years as a faculty member. In these three years I have accomplished the following: Presentations: 20 (from 2007-11), Publications: 5, Work in Progress: 5 manuscripts, all at different stages On going empirical research projects: 4 I owe all of the above and my passion and love for learning either directly or indirectly to the courses I took at XYZ.

Another participant mentioned, "Every aspect of topics addressed in the EdD program was relevant. When I returned to work after completing the program, I was able to blend right back into expectations that were occurring in my institution and not miss a beat." A participant wrote, "I believe the leadership courses helped to mold me into a leader that seeks collaboration; consensus; and values others' opinions." Another participant said, "I graduated from the program 8 years ago and it is amazing how much I learned that I still use on a daily basis. The readings and theory I was introduced to have definitely influenced my personal and professional life for the better." In another comment, a student participant mentioned, "The best cohort experience was the cohort project where we traveled to Costa Rica to study their educational system and their culture." Next participant wrote, "I was given the freedom to select specific elective courses that matched my personal and professional interests. I believe the program did challenge me to think critically and creatively. It did broaden my horizons." One comment was towards suggestions and the participant wrote, "I did not feel that the courses applied to my professional life, since I am in higher education and most of the courses were geared toward public school."

In short, strategies on becoming an effective leader, how to embrace and enjoy research, getting to share insights and perspectives from personal and professional experiences had a positive impact on the doctoral students. One student felt the combination of a Higher Ed and K-12 cohort did not allow the program to focus equally on both aspects of education. Another student believed 
the program should collaborate with the [State] Department of Education to create an automatic certification for superintendency.

\section{Overall Evaluation of the Program}

This section provided students an opportunity to list additional comments related to dissertation completion and/or their competency in their capabilities for program and dissertation. As seen in Table 6, 46 students were satisfied with the program, one was not satisfied and one was neutral.

Table 6. Overall Evaluation

\begin{tabular}{|c|c|c|c|c|c|c|}
\hline & Count & $\%$ & $M$ & $S D$ & Skewness & Range \\
\hline 1. Strongly Dissatisfied & -- & -- & 4.48 & 0.65 & -1.362 & 3 \\
\hline 2. Not Satisfied & 1 & 2.1 & & & & \\
\hline 3. Neutral & 1 & 2.1 & & & & \\
\hline 4. Satisfied & 20 & 41.7 & & & & \\
\hline 5. Highly Satisfied & 26 & 54.2 & & & & \\
\hline Total & 48 & 100.0 & & & & \\
\hline
\end{tabular}

Note. $N=48$

On the positive side of the comments, participants mentioned overall experience as being a member of cohort program of EdD program. A participant mentioned, "My experience was GREAT in a personal and professional perspective. In consideration of the XYZ EdD program as a professional career experience, I can say having graduated at age 56 the degree added another 13 years to my career." The second participant wrote, "The requirements for the program were appropriate. The dissertation took longer than I had planned. Technology has changed the way 'we do business' but I would suggest that being in the classroom with my cohort members was a key part of my learning. In other words, the face to face discussions were invaluable to me and I suggest that it continues rather than relying too much on technology to take the place of student/teacher interaction/engagement." Another participant shared, "The cohort model with face to face teaching is the most effective model for teaching leadership." The next comment was, "I was very satisfied with the program and have a great deal of respect for the instructors who teach it. I don't think I would change anything related to the completion of the program or dissertation."

Another positive comment was, "I am very pleased with the XYZ Cohort model. I've developed friendships throughout the program that helped to encourage each of us. There is plenty of time to complete the program. I, unfortunately, took every last minute to complete my dissertation, which I should have completed in about three years. For people that work best with structure, I recommend that the advisors set up completion dates for the doctoral candidate as they write their dissertation" Another comment goes like this, "I think the program is of high quality. I am currently a faculty member in educational leadership at a university in another state and have taught at several other universities, as well. I've also had the opportunity to sit on several NCATE site visit committees, so I have a fairly broad perspective on program quality. I think the XYZ doctoral program stands above others in the region."

In this study, we received some suggestions in this component. One comment was, "It would have been helpful if more information on writing the dissertation was included in the program. More direction on suitable topics for a dissertation, instead of do research and then we will approve or disapprove." 
In short, students were satisfied with the doctoral program and the requirements. Many students strongly suggested that they would choose XYZ's EdD program again if given the chance and would recommend the program to others. Students also liked the cohort model of instruction and felt the face-to-face sessions were effective in leadership education. Two students stated that the doctoral program could benefit by having more information readily available to students on the dissertation component of the program. Another student thought that the program could benefit from additional feedback from professors. While another student felt the program could improve by adding a class on gender issues in leadership.

\section{Limitations of the Study}

This exploratory case study identified the cohort-based model doctoral program in Educational Leadership based on the perceptions of graduates from one university doctoral program. Although the sample came from students who graduated from one EdD program from 1992 to 2010, participants from multiple institutions may provide diverse and strong viewpoints while reporting the perceptions of students about a cohort model doctoral program. A key limitation of this report lies in its exclusive focus on the doctoral program. This study also did not include the perceptions of faculty of the doctoral program. Their experiences and resources regarding the rigor of the program would add additional value if included in this study. The study excluded doctoral students who had not completed their dissertations or those students who were currently pursuing their course work at the time of study. The researchers would find a different result if those students were included in the study. With the consultation of the faculty and administrators, the researchers excluded demographic items such as age, gender, ethnicity, degree from the online survey to protect the identity of the participants. With this limitation, the researchers did not construct any hypothesis to test in this study, nor performed any advanced level of statistical analysis. The authors also acknowledged the two year time delay from when the survey was launched to when the paper was submitted for consideration as a limitation of this study. Overall, the results from this study may not be generalizable for a different population and setting because of its limitations. Despite these limitations in this study, the findings of this study are still useful in understanding the experiences and perceptions of graduate students in cohort model doctoral program, and it may contribute to the existing literature.

\section{Conclusions and Recommendations}

This study reported the student perceptions and included student reflections pertaining to the doctoral program at XYZ University. The results found the doctoral program to be successful in six assessment categories-- Curriculum $(M=4.48, S D=0.71)$, Program Structure $(M=4.67, S D=$ $0.48)$, Faculty $(M=4.5, S D=0.83)$, Learning Environment $(M=4.65, S D=0.53)$, Outcomes $(M=$ 4.58, $S D=0.65)$ and Overall Evaluation $(M=4.48, S D=0.65)$. These categories measured student perceptions in Curriculum, Program Structure, Faculty, Learning Environment, Outcomes, and Overall Evaluation.

Student perceptions on Curriculum overall showed that students surveyed were satisfied with the program curriculum $(M=4.48)$. Students felt the curriculum was relevant to their current profession and effectively prepared them for careers in K-12 or Higher Education. Students also believed the curriculum to be comprehensive, balanced, and rigorous. Student perceptions on the Program Structure component found students were highly satisfied $(M=4.67)$ with the class schedule, degree requirements, and manageability of courses. Students enjoyed the convenience of having two classes that met one night per week, which benefited those who were employed. Students stated the comprehensive examination requirements were well-conceived and manageable; however, many appreciated having alternatives to the comprehensive exam. Student perceptions of Faculty showed that students were very satisfied $(M=4.50)$ with the quality of 
teaching, expertise, involvement, and expectations of the program faculty. Faculty was perceived as caring, helpful, and knowledgeable in their field. Students felt the professors offered different perspectives of the topics in class discussions, were professional and supportive, and had high expectations of students.

The majority of the students were found to be satisfied $(M=4.65)$ with the Learning Environment of the program. Students believed the library had excellent resources that were readily accessible. Students liked the size of the cohort and the peer interaction. Students felt it was a supportive atmosphere. Ninety-One percent of the students were satisfied $(M=4.58)$ with the Outcomes. Students feel they have been able to successfully apply what they have learned in their professional lives. Students claimed they became more insightful, a more effective leader, and learned how to embrace and enjoy research. Students felt the program challenged them to think critically and creatively, and allowed them to apply new perspectives in their profession.

Overall the results indicated support $(M=4.48)$ for the EdD doctoral program at XYZ University. The cohort structure provided students with not only support from professors, but also support from their peers. Students felt the curriculum was comprehensive and relevant, believed the course load to be manageable yet challenging, the faculty to be knowledgeable and encouraging, and the atmosphere to be supportive. Students believed the program to be relevant to their current profession and effectively prepared them for careers in K-12 or Higher Education.

In the context of current study, the authors recommend several future studies to examine the overall impact of cohort based doctoral program in education. First, a comparative study that uses the perceptions of doctoral students and their faculty would strengthen the study. Second, a large sample that includes participants who have completed the dissertations or currently working on their dissertation or simply taking course work would lead a meaningful result to generalize its findings for a larger population. In fact, this current study is a case study based on the perceptions of the cohort-based model graduate students in Educational Leadership program at a midsouthern university in the United States. Third, a future research that includes participants from multiple universities as well as multiple disciplines would offer a significant direction to assess the experiences and perceptions of graduates in doctoral programs. Forth, a revised and well tested instrument is recommended. Fifth, the researchers strongly recommend the use of demographic information such as age, gender, ethnicity, degree in previous level are strongly recommended in any future research so that inferential statistics could be used to explore further relations and association of components.

\section{Acknowledgements}

We would like to thank George Foldesy, Pamela Shultz, and Sanoya Amieny for their suggestions and comments while reading earlier draft of this manuscript. We are also grateful to the reviewers and editors for their insightful suggestions.

\section{References}

Augusto, J. S. (2009). Case studies of EdD and PhD dissertations in educational administration. (Unpublished doctoral dissertation). University of Kansas, Kansas.

Baez, B. (2002). Degree of distinction: The EdD or the PhD in education. A paper for the Annual Meeting of the Association for the Study of Higher Education, Sacramento, California, November 21-24. Retrieved from http://www.usc.edu/dept/chepa/pdf/ASHE_baez.pdf

Barnett, B. G., \& Caffarella, R. (1992). The use of cohorts: A powerful way of addressing issues of diversity in preparation. Minneapolis, MN: University Educational Council for Administration. (Eric Document Reproduction Service No. ED354627). 


\section{Cohort-Based Doctoral Programs}

Basom, M., \& Yerkes, D. (2001, April 12). Modeling community through cohort development. Retrieved from ERIC database (ED451814).

Bentley, T., Zhao, F., Reames, E. H., \& Reed, C. (2004). Frames we live by: Metaphors for the Cohort. The Professional Educator, 26(2), 39-44. Retrieved from http://theprofessionaleducator.org/articles/archives/spring2004.pdf\#page $=43$

Bolman, L. G., \& Deal, T. E. (2013). Reframing organizations: Artistry, choice, and leadership (5 $5^{\text {th }}$ ed.). San Francisco, CA: John Wiley \& Sons.

The cohort model. (2012). New doctoral program (EdD) in Educational Leadership, California State University at Northridge. Retrieved from http://www.csun.edu/education/doctorate/program/cohort.html

Creswell, J. W. (2005). Research design: Qualitative and quantitative approaches. Thousand Oaks, CA: Sage Publications.

Eifler, K. E., Potthoff, D., \& Dinsmore, J. (2004). A bucket of EELS: A tripartite approach to renewing a teacher education program. Journal of Teacher Education, 55(1), 91-101.

Freeman, S., \& Kochan, F. K. (2012). Academic pathways to university leadership: Presidents' descriptions of their doctoral education. International Journal of Doctoral Studies, 7, 93-124.

Gardner, S. K., \& Gopaul, B. (2012). The part-time doctoral student experience. International Journal of Doctoral Studies, 7, 63-78. Retrieved from http://ijds.org/Volume7/IJDSv7p063-078Gardner352.pdf

Govender, K., \& Dhunpath, R. (2011). Student experiences of the PhD cohort model: Working within or outside communities of practice. Retrieved from http://utlo.ukzn.ac.za/Libraries/November_2011_Conferences/Student_Experiences_of the_PHd_Coh ort_Model_of_Supervision.sflb.ashx

Hallinger, P. (2011). A review of three decades of doctoral studies using the Principal Instructional Management Rating Scale: A lens on methodological progress in Educational Leadership. Educational Administration Quarterly, 47(2), 271-306. doi:10.1177/0013161X10383412

Holman, D., Oleson, S., \& Wesson, L (1996). A closed cohort: What students are telling us after four years. Paper presented at the annual meeting of the Southern Regional Council on Educational Administration, Savannah, GA.

Hyatt, L., \& Williams, P. E. (2011). 21 st century competencies for doctoral leadership faculty. Innovative Higher Education, 36(1), 53-66. doi:10.1007/s10755-010-9157-5

Ivankova, N. V., \& Stick, S. L. (2007). Students' persistence in a distributed doctoral program in educational leadership in higher education: A mixed methods study. Research in Higher Education, 48(1), 93-135. doi:10.1007/s11162-006-9025-4

John-Steiner, V., \& Mahn, H. (2003). Sociocultural contexts for teaching and learning. In I. B.Weiner, W. M. Reynolds, \& G. E. Miller (Eds.), Handbook of psychology: Vo. 7 Educational psychology (pp. 125148). New York, NY: John Wiley \& Sons, Inc.

LaMorte, W. W. (2012). Prospective versus retrospective cohort studies. Boston University. Retrieved from http://sph.bu.edu/otlt/lamorte/EP713/Web_Pages/EP713_CohortStudies/EP713_CohortStudies2.html

Lei, S., Gorelick, D., Short, K., Smallwood, L., \& Wright-Porter, K. (2011). Academic cohorts: Benefits and drawbacks of being a member of a community of learners. Education, 131(3), 497-504. Retrieved from http://eric.ed.gov/?id=EJ996368

Lewis, S. V., Ascher, D., L., Hayes, B. G., \& Ieva, K. P. (2010). Counselor education doctoral cohorts: Growth, reflections, and success. Retrieved from http://counselingoutfitters.com/vistas/vistas10/Article_25.pdf

Loyola University at Chicago. (2011). Loyola University Chicago Cohort Program. Retrieved from http://www.luc.edu/ccse/CE_MEdCohort.shtml 
Maher, M. (2005). The evolving meaning and influence of cohort membership. Innovative Higher Education, 30(3), 195-211.

McCarthy, J., Trenga, M., \& Weiner, B. (2005).The cohort model with graduate student learners: FacultyStudent perspectives. Adult Learning, 16(3\&4), 22-25.

McPhail, C. J., Robinson, M., \& Scott, H. (2008). The cohort leadership development model: Student perspectives. Community College Journal of Research and Practice, 32(4-6), 362-374. doi:10.1080/10668920701884539

Merriam, S. (1998). Qualitative research and case study applications in education. San Francisco, CA: Jossey-Bass Publishers.

Mountford, M. (2005). The journey toward transformational learning in a statewide doctoral program. Innovative Higher Education, 30(3), 213-227. doi:10.1007/s10755-005-6305-4

Mountford, M., Ehlert, M., Machell, J., \& Cockrell, D. (2007). Traditional and personal admissions criteria: Predicting candidate performance in US educational leadership programs. International Journal of Leadership in Education, 10(2), 191-210. doi:10.1080/13603120600935696

Nimer, M. (2009). The doctoral cohort model: Increasing opportunities for success. College Student Journal, 43(4), 1373-1379.

Pemberton, C. L., \& Akkary, R. K. (2010). A cohort, is a cohort, is a cohort ... Or is it ? Journal of Research on Leadership Education, 5(5), 179-208.

Poole, B. (2011). Notes on the emergence of EdD (Doctor of Education) programmes in the United Kingdom. Journal of the NUS Teaching Academy, 1(1), 44-53.

Potthoff, D. E., Batenhorst, E. V., Frederickson, S. A., \& Tracy, G. E. (2001). Learning about cohorts: A master's degree program for teachers. Action in Teacher Education, 23(2), 36-42.

Purinton, T. (2012, May 20). The EdD dilemma. Education Week. Retrieved from http://www.edweek.org/ew/articles/2012/05/16/31purinton.h31.html

Rost, J. C. (1991). Leadership for the twenty-first century. New York, NY: Praeger Press.

Sax, L. J. (2008). The gender gap in college: The developmental maximizing potential of women and men. San Francisco, CA: Jossey-Bass.

Seed, A. (2008). Cohort building through experiential learning. Journal of Experiential Education, 31(2), 209-224.

Seifert, K., \& Mandzuk, D. (2006). Student cohorts in teacher education: Support groups or intellectual communities? Teachers College Record, 108(1), 1296-1320.

Spaulding, L. \& Rockinson-Szapkiw, A (2012). Hearing their voices: Factors doctoral candidates attribute to their persistence. International Journal of Doctoral Studies, 7, 199-219. Retrieved from http://ijds.org/Volume7/IJDSv7p199-219Spaulding334.pdf

Student Handbook. (2012). Doctor of Education in Educational Leadership. XYZ University, City, State removed.

Tashakkori, A., \&Teddlie, C., (Eds.) (2003). Handbook on mixed methods in the behavioral and social sciences. Thousand Oaks, CA: Sage Publications.

Teitel, L. (1997). Understanding and harnessing the power of the cohort model in preparing educational leaders. Peabody Journal of Education, 72(2), 72-85.

Tokuno, K. A. (2008). Theories relating to the transition into graduate study. In K. A. Tokuno (Ed.), Graduate students in transition: Assisting students through the first year (Monograph No. 50, pp. 2746). Columbia, SC: University of South Carolina, National Resource Center for the First-Year Experience and Students in Transition. 
Toma, D. J. (2002). Legitimacy, differentiation, and the promise of the Ed.D. in higher education. Paper presented at the Annual Meeting of the Association for the Study of Higher Education: Education Resource Information Center, pp. 11-12. Retrieved from http://files.eric.ed.gov/fulltext/ED482308.pdf

Unzueta, C, Moores-Abdool, W., \& Donet, D. (2008, March). A different slant on cohorts: Perceptions of professors and special education doctoral students. Paper presented at the annual meeting of the American Educational Research Association, Miami, FL.

Wesson, L. H., Holman, S. O., Holman, D., \& Cox, D. (1996). Cohesion of collusion: Impact of a cohort structure on educational leadership doctoral students (Report \#HE 029407). New York, NY: Annual Meeting of the American Educational Research Association. (ERIC Document Reproduction Service \#ED 398809).

Williams, D., \& Simpson, M. (2010). Learning in online community: A model of doctorate level Internetenhanced education. Common Ground Journal, 2(7), 32-56.

Young, I. (2007). Predictive validity of grade point averages and of the Miller Analogies Test for admission to a doctoral program in educational leadership. Educational Research Quarterly, 31(2), 44-55.

\section{Biographies}

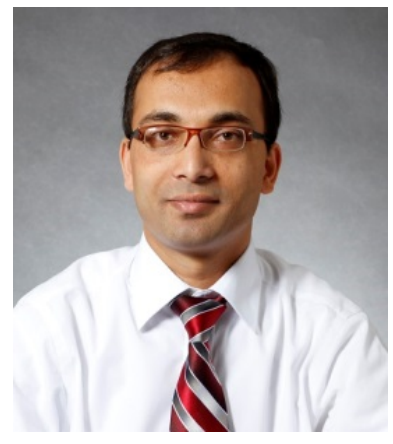

Krishna Bista, EdD, is an Assistant Professor in the School of Education at the University of Louisiana at Monroe, USA. His research interests include leadership practices, profession development, and international higher education. Krishna is a member of American Educational Research Association, Mid-South Educational Research Association, and Professional Organization and Development (POD) Network in Higher Education. He can be reached at bista@ulm.edu.

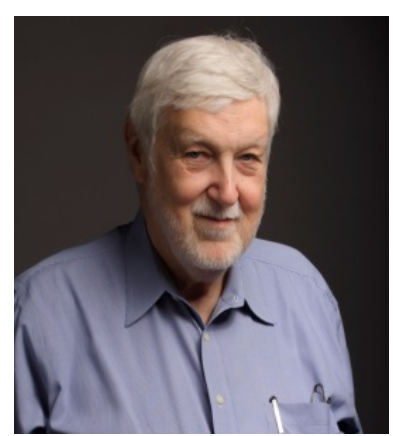

David W. Cox, EdD, is a Professor of Education and coordinator of Community College Education Program in the Center for Excellence in Education at Arkansas State University, USA. His special interests include leadership development, organization development, open space technology, college teaching, and experiential learning. He can be reached atdwcox@astate.edu. 